\title{
APROXIMACIÓN A LOS PERSONAJES DEL CORRIDO MEXICANO*
}

María del Carmen Garza**

Uno de los problemas más serios que se presentan al emprender un estudio sobre el corrido mexicano es el de la heterogeneidad de los materiales. Un grupo muy numeroso, formado por los que han tenido mayor difusión y presentan gran cantidad de rasgos folklóricos. está constituido por textos en los que la secuencia de las acciones aparece integrada en una sola unidad de acción, por lo que les he llamado corridos-tragedia. En ellos se cumplen también otras características que señala Aristóteles para la tragedia, las cuales refuerzan la elección de esta denominación, como: hacer del hombre el tema central, la presentación de hechos y características verosímiles o posibles, la desventura como desenlace de la acción, la fatalidad que actúa como Deux ex machina, la figura del héroe trágico y la intención de la tragedia de educar al pueblo.'

* Trabajo presentado en el 3er. Coloquio Internacional del Romancero, Universidad Complutense de Madrid, 1994.

** Lingüista por El Colegio de México.

${ }^{1}$ Cfr. Aristóteles, Poética, versión de J. D. García Bacca, 1946, México, UNAM, Biblioteca Scriptorum Graecorum et Romanorum Mexicana, Obras completas de Aristóteles, p. 7-38. 


\section{MARÍA DEL CARMEN GARZA}

En estos corridos-tragedia uno de los aspectos que llaman más poderosamente la atención es la persistente autoafirmación del hombre, que le lleva a una actitud agresiva ante todos sus semejantes. Aparece siempre un hombre (personaje masculino) que entra en conflicto con alguien que se le opone. De esta manera, hay constantemente una oposición que puede presentarse como Yo/Otro. Este Yo, que busca su autoafirmación, se considera a sí mismo un ser positivo y ve_en todos los demás, representados en el Otro, sólo rasgos negativos, por lo que la confrontación no se hace esperar. Así encontramos que, en actitud de héroe, constantemente trata de afirmar su individualidad a costa de los otros, con base en bravuconadas y en actitud de reto:

Gritaba Jesús Cadenas:

«Yo soy hombre donde quiera, y el que no lo quiera creer no más que se salga afuera»", ${ }^{2}$

lo cual lo lleva a enfrentarse a su adversario a sangre fría y considerar el pleito armado como un pasatiempo:

Decía don Demetrio Jáuregui abrochándose un zapato:

«Aquí traigo hartos casquillos pa divertirles un rato.» ${ }^{3}$

Los desplantes de machismo son constantes. Por una parte el héroe presume de su valor y por otra fanfarronea de su posibilidad de enfrentarse no a uno sino a muchos adversarios:

${ }^{2}$ «Versos de la güera Chabela» (autor: Leopoldo Bravo), hoja suelta, vs. $57-60$.

3 «Demetrio Jáuregui» (anónimo), Bajío; Higinio Vázquez Santana, Canciones, cantares y corridos mexicanos, [1924?], México, M. León Sánchez, p. 271-4, vs. 25-8. 
Decía Guadalupe Rayos:

«No será la primer vez, pues yo siempre me he jugado

con cinco, seis o con diez.» ${ }^{4}$

«Para el héroe de los corridos el concepto de su valor está en estrecha relación con el juicio de los demás. Necesita recibir muestras de aceptación que le sirvan para autoafirmarse y testimoniar su mérito, y toda circunstancia que lo hace aparecer como individuo de menor valía provoca una reacción de defensa. Ya que su escala de valores tiene como extremos la cobardía y el valor sin límites, él debe ser considerado en el nivel más alto.» 5

De esta manera, cuando tiene que enfrentarse a un contrario, está siempre dispuesto a llevar las consecuencias hasta el final:

Alguien le corrió a avisar:

-Bernal, ahí viene la tropa.

-Aquí los voy a esperar,

a ver a cómo nos toca. ${ }^{6}$

Y Guadalupe le dice:

«No venimos a correr,

hoy nos damos de balazos

hasta morir o vencer.» ${ }^{7}$

En este terreno no hay ninguna posibilidad de transigir, y el héroe prevalecerá sobre cualquiera que se le oponga dominándolo a base de la valentía y el poder que le otorgan las armas:

4 «Guadalupe Rayos» (anónimo), San Felipe Torres Mochas (Guanajuato); Vicente T. Mendoza, Lírica narrativa de México. El corrido, 1964, México, UNAM, Inst. de Inv. Estéticas, p. 201-2, vs. 17-20.

${ }^{5}$ María del Carmen Garza Ramos, «Fisonomía del héroe en el corrido mexicano», Diálogos, (nov. dic. 1968), p. 13.

${ }^{6}$ «Nacho Bernal» (anónimo), Mendoza, op. cit., p. 203-4, vs. 21-4.

7 «Guadalupe Rayos» (anónimo), id., p. 202-3, vs. 29-32. 
MARÍA DEL CARMEN GARZA

«Ve sacando tu pistola, dices que eres muy valiente, para darnos tiro a tiro y darnos una caliente. ${ }^{8}$

Así, el héroe del corrido presenta una personalidad en la cual domina la fanfarronería y la arrogancia, por lo que son constantes los alardes de machismo:

Heraclio Bernal decía camino de Mazatlán:

«Ni un pelo nos han tocado y mira cómo se van.» ${ }^{9}$

Decía Benito Canales ya después de confesado: «Quiero pelear otro rato ahora que estoy descansado.» ${ }^{10}$

Si en un duelo debe actuar con valentía y heroísmo, cuando el personaje del corrido-tragedia recibe una sentencia de muerte es donde debe demostrar verdaderamente su valor, al esperar fría y pacientemente que lo fusilen. En estos casos se insiste en la valentía del personaje y se narra detalladamente la actitud ante su propia muerte:

Ángeles puso un mensaje

al Congreso de la Unión:

«Que si he de ser fusilado, ya estoy en disposición.

8 «José Villanueva» (autor: Felipito Rivera), San Luis de la Paz (Guanajuato); id., p. 235-6, vs. 25-8.

${ }^{9}$ «Heraclio Bernal» (anónimo), Magistral, Santa Maria del Oro (Durango); Vicente T. Mendoza, El romance español y el conido mexicano. Estudio comparativo, 1939, México,UNAM, p. 442-3, vs. 57-60.

10 «Benito Canales» (anónimo), hoja suelta, vs. 105-8. 
Yo no soy de los cobardes que le temen a la muerte, la muerte no mata a nadie, la matadora es la suerte.

El reloj marca las horas, se acerca mi ejecución, preparen muy bien sus armas y apúntenme al corazón.

No se muestren tan cobardes ni manifiesten tristeza, que a los hombres como yo no se les da en la cabeza.

Aquí está mi corazón para que lo hagan pedazos, porque me sobra el valor de recibir los balazos.» ${ }^{11}$

Aquí, cuando el héroe va a morir fusilado, es el único caso en donde se insinúan algunos matices de su personalidad. Los actantes de corridos-tragedia corresponden a tipos literarios pues presentan una sola faceta, rígida y uniforme; sólo en esta situación a base de reacciones contrastadas aparece el intento de crear un verdadero personaje. $\mathrm{Si}$ el héroe se enfrenta al pelotón de fusilamiento sin el menor asomo de temor, mostrando plenamente su hombría y alardeando de ella, no por eso es un ser insensible; para mostrar esto último, se presentan momentos previos de angustia y de temor y, a base de brochazos, se colorea una personalidad que de otra manera resultaría chata y poco convincente:

11 «Felipe Ángeles» (anónimo), Jesús Romero Flores (ed.), Anales Históricos de la Revolución Mexicana. Sus corridos, 1941, México, E1 Nacional, p. 195-7, vs. 77-96. 
MARÍA DEL CARMEN GARZA

Cuando llegó a su destino

dijo: «Vengo en agonía

pues hoy tengo que ser muerto;

Dios así los dispondría.»

«Oiga usted, mi general,

yo también fui hombre valiente,

quiero me haga ejecución

a la vista de la gente.»

«Ya que Dios me ha concedido

el no morir en la guerra,

quiero que a mi alma en camino

anime Cristo en la tierra.»

«Adiós todos mis amigos, me despido con dolor; ya no vivan tan engreídos de este mundo engañador.»

«Adiós también el reloj, tus horas me atormentaban, pues clarito me decían las horas que me faltaban.»

«Amigo, no te señales por riqueza ni estatura, pues todos somo iguales: materia de sepultura.» ${ }^{12}$

El héroe de los corridos-tragedia «pertenece a un mundo poético en el cual el atributo supremo es la valentía, y la persona más admirada es la que hace alardes de hombría, pues para probar que es valiente no

12 «Benjamín Argumendo» (anónimo), Coahuila; Mendoza, Lírica narrativa..., p. 172-3, vs. 37-40, 49-52, 61-8, 81-8. 
le importa morir y ve a la muerte de frente, cara a cara. En el corrido mexicano se oponen muerte y valor en un desafío constante; el que llega a morir se transforma en héroe y, sin que importe el tipo de hombre que fue durante su vida, recibe el reconocimiento y la admiración de todos y sigue viviendo convertido en el personaje de un corrido». ${ }^{13}$

Al analizar las figuras femeninas que aparecen en los corridos-tragedia debemos considerar dos categorías independientes: por una parte, la mujer en su papel de amante, o sea la mujer a la que se pueden hacer requerimientos amorosos, y por otra la mujer en su papel de madre.

Esta mujer-amante, en su relación con el hombre, ocupa el sitio que le corresponde al Otro, por lo cual lleva consigo una carga negativa que la hace aparecer como la infame, la infiel, la ingrata.

El hombre «no ve en la mujer ninguna cualidad positiva; ella lo debe obedecer incondicionalmente y ha de guardar siempre una actitud pasiva; es una mujer-objeto, a quien no se le da ninguna libertad ni se le permite la menor iniciativa, pues su papel se reduce a aceptar al hombre que la busca. Cuando una mujer rompe con este esquema sobrevive la tragedia: si el hombre castiga con la muerte al que pone en duda su valor, la mujer que se atreve a desdeñarlo en sus requerimientos amorosos no merece mejor suerte»: ${ }^{14}$

Hipólito llegó al baile

y a Rosa se dirigió,

como era la más bonita

Rosita lo desairó.

-Rosita, no me desaires,

la gente lo va a notar.

-Pues que digan lo que quieran,

contigo no he de bailar.

${ }^{13}$ María del Carmen Garza de Koniecki, «La muerte en la poesía popular mexicana), Actas del Tercer Congreso Internacional de Hispanistas, 1970, México, El Colegio de México, p. 408.

${ }^{14}$ Garza Ramos, op. cit., p. 14. 


\section{MARÍA DEL CARMEN GARZA}

Echó mano a la cintura

y una pistola sacó;

a la pobre de Rosita

no más tres tiros le dio. ${ }^{15}$

El rechazo por parte de una mujer lo siente el hombre como una ofensa y entonces la mata; los ataques que se lanzan contra ella son constantes y se justifica el asesinato:
Pueblito de San Antonio, distrito de Moroleón, murió Cuquita Mendoza por jugar una traición. ${ }^{16}$
Cárcel de Guadalajara, cárcel de siete paredes, donde encierran a los hombres por las ingratas mujeres. ${ }^{17}$

En muchas ocasiones, cuando la mujer está a punto de morir, se arrepiente de haber tenido la osadía de rechazar a un hombre y reconoce su error:

Rosita le dice a Irene:

«No te olvides de mi nombre:

cuando vayas a los bailes

no desprecies a los hombres. ${ }^{18}$

${ }^{15}$ «Rosita Alvírez» (anónimo), Disco RCA Victor MKL-1521, «Corridos famosos del tiempo de la Revolución», lado A, vs. 9-20.

${ }^{16}$ «Cuca Mendoza» (anónimo), Higinio Vázquez Santana, Canciones, cantares y corridos mexicanos, t. 2, 1925, México, p. 251-2, vs. 1-4.

17 «Hipólito y Rosita» (anónimo), Mendoza, El romance..., p. 499, vs. 17-20.

18 «Rosita Alvírez» (anónimo), tradición oral, México, D. F., vs. 25-8. 
Decía la güera Chabela

cuando se estaba muriendo:

«Pongan cuidado, muchachas,

miren cómo van viviendo.) 19

Si la mujer, a nivel de amada o amante, está relegada a un nivel secundario, aparece como un ser subordinado y es valorada negativamente, la madre en cambio ocupa un sitio muy importante; ella posee un sentido especial que le permite intuir los peligros que acechan al hijo o a la hija:

Su madre se lo decía:

«Cuídate de una traición;

no vayas, hijo de mi alma,

me lo dice el corazón.» ${ }^{20}$

Cuando la madre lanza una prohibición, se puede insistir en la obediencia que el hijo debe a los padres, o presentar un contraste entre la visión profética de los acontecimientos por parte de la madre y la ceguera absoluta del hijo que, a pesar de las advertencias recibidas, no percibe el peligro:

Su madre se lo decía

que a ese fandango no fuera;

los consejos de una madre

no se llevan como quiera.

Llegaron a la cantina, se pusieron a tomar, pero Lucio no sabía que lo iba a traicionar. $^{21}$

${ }^{19}$ «La güera Chabela o Jesús Cadenas» (anónimo), Michocán, Mendoza, El romance, p. 478-9, vs. 57-60.

${ }^{20}$ «Lucio Vázquez» (anónimo), Sonora, id., p. 430-1, vs. 9-12.

${ }^{21}$ «Lucio Pérez»( anónimo), México D. F., id, Lirica narrativa..., p. 260-2, vs. 9-16. 


\section{MARÍA DEL CARMEN GARZA}

Otras veces se da sólo la prohibición e inmediatamente después la rebeldía del hijo que le lleva a transgredirla, pero el oyente, que conoce ya el poder de vaticinio de la madre, queda en una situación desde la cual, consciente ya del peligro que acecha al hijo o a la hija, contempla cómo se encamina irreflexivamente hacia él:

-No salgas, hijo de mi alma, porque te van a matar; tres hermanos ofendidos no te pueden perdonar.

-Madre, no les tengo miedo porque también sé pelear; al único que le temo:

a Dios, que me ha de juzgar. ${ }^{22}$

La madre debe ser obedecida siempre, y esto resalta más dramáticamente en su relación con el hijo. Si el hombre exige que la mujer a la que busca y corteja se le entregue sin restricción, él mismo tiene que obedecer a su madre incondicionalmente. Además, si el hijo es un hombre valiente, dispuesto a usar las armas para hacerse valer, la madre, $y$ en algunas ocasiones el padre, tiene otra arma, poderosa y siempre eficaz: la maldición. Aquí aparecen los padres como dueños absolutos del destino de sus hijos; las normas por ellos impuestas deben ser acatadas siempre, y la imposición de su autoridad se superpone a las relaciones de afecto.

He aquí un ejemplo de corrido con maldición:

Un sábado por la tarde

Benjamín se fue a cobrar

y junto con sus amigos

se fueron a emborrachar.

22 «Tres viudas solas» (anónimo), Marcela Ruiz de Velasco Padierna, Estado actual del corrido en Monterrey, N. L., 1965, México, Univ. Iberoamericana, Fac. de Fil. y Letras, [Tesis], p. 162, vs. 5-12. 
Benjamín se fue a su casa, su mamá lo regañó, pero Benjamín le dijo: «El dinero lo gano yo.»

La madre, como enojada, un maldición le echó delante de un Santo Cristo que hasta la tierra tembló:

«Permita Dios, hijo mío, permitan todos los santos, cuando llegues a la mina te saquen hecho pedazos.)

Benjamín se fue a la mina y no queriendo trabajar, pero uno de sus amigos no lo quiso relevar.

Bajó el primer escalón, el segundo se rompió, $y$ uno de sus amigos en un paño lo sacó.

Vuela, vuela palomita, párate en aquel panteón en donde está Benjamín muerto por la maldición. ${ }^{23}$

En algunas ocasiones en que el hijo muere por la maldición de la madre, cuando ésta se entera de lo ocurrido puede aparecer nuevamente para expresar su pesar y su arrepentimiento:

${ }^{23}$ «Benjamín» (anónimo), Minas de Rosita y Palau (Coahuila); Mendoza, Lírica narrativa..., p. 260. 


\section{MARÍA DEL CARMEN GARZA}

Le avisaron a la madre y un gran desmayo le dio; alzó los ojos al cielo y al momento se acordó.

La pobre madre lloraba muy triste y desconsolada, pero ya todo era en vano las lágrimas que regaba.

La madre se confundió cuando lo miró tendido: «Te fuiste y me dejaste, adiós, hijito querido.»

«Perdónanuc, Padre mío, las faltas que he cometido; el demonio me tentó y a mi hijo he maldecido.» ${ }^{24}$

De esta manera, la figura de la madre es ambivalente: el sufrimiento contrasta con la dureza con que lanza la maldición. El dolor por la muerte del hijo es una de las constantes en el corrido-tragedia:

Su pobre madre lloraba con un dolor muy profundo, porque su hijo querido ya había partido del mundo. ${ }^{25}$

La madre, cuando lo supo, sus ojos eran cristales,

24 «José Lizorio» (autor: Juan Montes), hoja suelta, vs. 77-92.

25 «Rafael Picazo» (anónimo), Chavinda (Michoacán), Mendoza, El romance, p. 497-8, y Mendoza, Lírica narrativa..., p. 244, vs. 13-6. 
LOS PERSONAJES DEL CORRIDO

de ver a su hijo querido

con tres heridas mortales. ${ }^{26}$

En muchos casos, cuando el hijo está moribundo la madre aparece a su lado acompañándolo en sus últimos instantes, sin que se indique cómo se enteró de lo ocurrido:

Su pobre madre lloraba

debajo de los portales:

«¿Cómo quieres levantarte,

si son heridas mortales?» ${ }^{27}$

También es frecuente que la madre acompañe durante las últimas horas al hijo que va a morir fusilado; en contraste con la entereza de éste, aparece el llanto insistente de la madre:

Le leyeron la sentencia

que lo iban a fusilar

y su pobre madrecita

luego comenzó a llorar. ${ }^{28}$

Esta unión afectiva de la madre hacia el hijo se observa también en reciprocidad, como en estas últimas palabras del hijo herido mortalmente:

«No llores, madre querida, no llores, niña del cielo,

${ }^{26}$ «Ramón Cabrera» (anónimo), Sahuaripa (Sonora), id., p. 577, e id., p. 233-4, vs. 17-20.

27 «Lucío» (sic) (anónimo), Michoacán, Frances Toor, A Treasury of Mexican Folkways, 1947, México Press, p. 400-1, vs. 21-4.

${ }^{28}$ «Jesús Cadenas» (autor: Leopoldo Bravo), Eduardo Guerrero (ed.), Corridos de amor y cantos sentimentales del pueblo mexicano, 1931, México, Guerrero, [90 hojas sueltas], vs. 61-4. 
MARÍA DEL CARMEN GARZA

va a morir tu hijo querido,

al cabo no es el primero», ${ }^{29}$

o en los mensajes que le envía el hijo ya muerto:

«Vuela, vuela palomita,

párate en aquella rama;

anda, ve y dile a mi madre

que me mataron $\sin$ arma. $)^{30}$

De esta manera aparece un aspecto más dentro de la personalidad del héroe, pues no se trata sólo del hombre valiente, arbitrario e insensible que elimina a sus contrarios porque es incapaz de sentir afectos. Ahí están sus reacciones ante la madre, aunque se trata de un mundo emocional precario y sin desarrollar, anquilosado en la primera etapa infantil e incapaz de comunicarse emocionalmente con la mujer o con otros hombres.

El examen de los corridos-tragedia nos lleva a los conceptos vida y muerte como elementos fundamentales, y cabe preguntarse ¿cuál es la percepción de la vida que se encierra detrás de todas estas muertes? Por lo general el corrido-tragedia se detiene en la valoración de las acciones y en las intenciones moralizantes, pero en ocasiones va más allá y entonces se considera que con la muerte se deja de sufrir:

Del cielo bajó un arcángel en un buque de gardenias a llevarse a Carlotita que ya se quitó de penas. ${ }^{31}$

${ }^{29}$ «Guadalupe Rayos» (anónimo), Mendoza, Lírica narrativa..., p. 202-3, vs. $37-40$.

${ }^{30}$ «Alfredo Arocha» (anónimo), Río Grande (Coahuila), id., p. 240-1, vs. 41-4.

${ }^{31}$ «Carlotita» (autor: Santiago Aguilera), Guerrero, op. cit., vs. 57-60. 
Triste final de esta historia que hoy acabo de contar, que Dios lo tenga en su gloria pues ya cesó de penar. ${ }^{32}$

Aquí, además del concepto de la vida como un valle de lágrimas conforme al catolicismo tradicional, hay una infravaloración de la vida. Para los personajes del corrido-tragedia la vida no significa nada, no vale la pena vivirla, y el narrador se identifica con esta visión. El mundo poético de los corridos-tragedia se desarrolla en torno a un problema vital: «La vida no significa nada, no ofrece ni perspectivas ni soluciones, y de esta manera vivir y morir vienen a resultar lo mismo. Ante la intrascendencia de una vida sin sentido ni justificación, la muerte brinda un camino distinto. ${ }^{33}$

Esto podemos advertirlo con claridad en el siguiente texto:

Vuela, vuela palomita, vuela si sabes volar y anda avísale a mi madre que me van a fusilar.

Así cantaba y decía en Puebla Cirilo Arenas que a la muerte no temía porque nos quita de penas. ${ }^{34}$

${ }^{32}$ «El general Felipe Angeles» (anónimo), Rubén M. Campos, El folklore literario de México, 1929, México, Talleres Gráficos de la Nación, p. 2636, vs. 105-8.

${ }^{33}$ Garza de Koniecki, op. cit., p. 409-10.

${ }^{34}$ «El fusilamiento de Cirilo Arenas en Puebla, el 4 de marzo de 1920» (anónimo), Eduardo Guerrero (ed.), Corridos históricos de la Revolución Mexicana desde 1910 a 1930 y otros notables de varias épocas, 1931, México, [106 hojas sueltas], vs. 1-8. 


\section{MARÍA DEL CARMEN GARZA}

El mundo poético que aparece en los corridos-tragedia está entresacado de ciertos aspectos de la sociedad mexicana y de su ambiente, por lo cual los personajes que en ellos aparecen corresponden a estereotipos, esto es, generalizaciones sobre el comportamiento o el carácter de un grupo social determinado, que aunque no correspondan a la complejidad de la sociedad que tratan de representar su visión no es necesariamente falsa. ${ }^{35}$

En el corrido-tragedia aparecen tres estereotipos del mexicano: el hombre valiente que se transforma en héroe, la madre y la mujer. Es interesante notar que estos estereotipos corresponden a algunas de las características que se han señalado en diversos estudios destinados a la definición del mexicano. Tanto el estudio ya clásico de Samuel Ramos, El perfil del hombre y la cultura en México, ${ }^{36}$ como El laberinto de la soledad de Octavio $\mathrm{Paz}^{37}$ o el análisis sobre «El carácter del Mexicano» de José Iturriaga, que forma parte de su obra La estructura social y cultural de México, ${ }^{38}$ el ensayo de Santiago Ramírez, El mexicano. Psicología de sus motivaciones, ${ }^{39}$ el de Aniceto Aramoni, Psicoanálisis de la dinámica de un pueblo, ${ }^{40}$ el de Jorge Carrión, Mito y magia del mexicano, y un ensayo de autocrítica ${ }^{41}$ o la obra de Roger Bartra, La jaula de la melancolia. Identidad y metamorfosis del mexicano, ${ }^{42}$ para no citar sino algunos de los estudios más relevantes, ${ }^{43}$ describen la naturaleza del mexicano y señalan entre las características del hombre: el machismo, la agresividad, la sus-

${ }^{35}$ Cfr. Raúl Béjar Navarro, El mito del mexicano, 1968, México, UNAM, Fac. de Ciencias Políticas y Sociales, p. $67 \mathrm{~s}$.

${ }^{36}$ 1938, 2a. aum, México, Robredo.

${ }^{37}$ 1967, 5a., México, F.C.E.

38 1951, México, F.C.E.

39 1959, México, Paz-México, Asociación Psicoanalítica Mexicana.

40 1961, México, UNAM.

41 1971, México, Nuestro Tiempo.

42 1987, México, Gredos.

${ }^{43}$ Para una bibliografía más amplia cfr. Béjar Navarro, op. cit., donde se resumen y critican unos cuarenta trabajos. 


\section{LOS PERSONAJES DEL CORRIDO}

ceptibilidad, el desprecio por la mujer, la indiferencia tanto ante la muerte como ante la vida; y entre las características de la mujer: la pasividad, su calidad de mujer-objeto, su valoración como ser inferior que sólo puede realizarse cuando, como madre, mujer-Virgen, impone su autoridad sobre los hijos.

Lo que se ha deseado añadir aquí es la coincidencia que se presenta entre los rasgos que aparecen en el corrido-tragedia y las observaciones hechas en los estudios sobre el carácter del mexicano. 